\title{
MÉTODOS DE COMPARAÇÃO DE CURVAS DE SOBREVIVÊNCIA
}

\author{
JANAÍNA PEREIRA
}

Bacharel em Matemática

Orientadora: Prof $\underline{\underline{a}}$ Dr $\underline{\underline{a}}$ Roseli Aparecida Leandro

Dissertação apresentada à Escola Superior de Agricultura "Luiz de Queiroz", Universidade de São Paulo, para a obtenção do título de Mestre em Agronomia, Área de Concentração: Estatística e Experimentação Agronômica.

PIRACICABA

São Paulo - Brasil

Dezembro - 2002 


\section{ERRATA}

JANAÍNA PEREIRA. Métodos de comparação de curvas de sobrevivência.

\begin{tabular}{|c|c|c|c|c|}
\hline p. & item & linha & Onde se lề & Leia-se \\
\hline iii & AGRADECIMENTOS & 13 & ...Arruda Chalita... & ...Arruda Silveira... \\
\hline & RESUMO & 3 & $\begin{array}{l}\text { resistência de } \\
\text { pragas... }\end{array}$ & $\begin{array}{c}\text { resistência } \\
\text { plantas a pragas... }\end{array}$ \\
\hline 7 & REVISÃO DE LITERATURA & 2 & ...observada a seguir... & $\begin{array}{l}\ldots \quad \text { observada nas } \\
\text { Figuras } 1,2 \text { e } 3 \ldots\end{array}$ \\
\hline 8 & REVISÃO DE LITERATURA & 10 & $\begin{array}{l}\ldots \text { o método de Tabela } \\
\text { de Vida e o Estimador } \\
\text { do Produto... }\end{array}$ & $\begin{array}{l}\text {.. Tabela de Vida e } \\
\text { Produto... }\end{array}$ \\
\hline & REVISÃO DE LITERATURA & 2 & $\ldots \mathrm{S}\left(\mathbf{t}_{\mathbf{k}}\right) \ldots$ & $\ldots \mathrm{S}\left(\mathrm{t}_{\mathrm{i}}\right) \ldots$ \\
\hline 14 & REVISÃO DE LITERATURA & 14 & $\ldots \mathrm{u}_{\mathrm{ij}} \quad \mathrm{e}_{\mathrm{ij} \ldots}$ & $\ldots u_{j} e_{i j} \ldots$ \\
\hline 15 & REVISÃO DE LITERATURA & 17 & ... 2.4.4 Teste... & ... 2.5 Teste... \\
\hline
\end{tabular}




\title{
Dados Internacionais de Catalogação na Publicação (CIP)
} DIVISÃO DE BIBLIOTECA E DOCUMENTAÇÃO - ESALQ/USP

\author{
Pereira, Janaína \\ Métodos de comparação de curvas de sobrevivência / Janaína Pereira. - - Piracicaba, \\ 2002. \\ 40 p. \\ Dissertação (mestrado) - - Escola Superior de Agricultura Luiz de Queiroz, 2002. \\ Bibliografia.
}

1. Análise de sobrevivência 2. Dados censurados 3. Estatística aplicada 4. Simulação (Estatistica) I. Título

CDD 519.5 
À minha força maior,

\section{Deus}

És a minha fortaleza, meu refúgio e meu grande guia. A ti entreguei a minha vida e hoje não poderia deixar de te dedicar o meu trabalho.

Aos meus pais, Vanildo e Zilda, pelo grande estímulo, dedicação e amor.

Ao meu grande amor, Romulo

pelo carinho, compreensão e amor. 


\section{AGRADECIMENTOS}

A Deus

No mundo tereis aflições, mas tendes bom ânimo, eu venci o mundo.

João 16:33.

À minha família, o incentivo, as palavras de conforto e carinho.

$\grave{\lambda}$ prof ${ }^{a} \operatorname{Dr}^{a}{ }^{a}$ Roseli Aparecida Leandro, a orientação, a dedicação e o carinho. Devo muito do que sou à você.

À prof ${ }^{a}$ Dr. $^{a}$ Clarice Garcia Borges Demétrio, os ensinamentos, conselhos, incentivo e carinho. Também lhe devo muito.

À Solange, sua sorriso, seu carinho e sua dedicação. Enquanto eu viver, vou lembrar de você.

Ao prof Dr. José Eduardo Corrente, os ensinamentos, a orientação e o carinho.

À prof ${ }^{a}$ Dr. ${ }^{a}$ Liciana Vaz de Arruda Chalita, a colaboração.

Aos professores e funcionários do Departamento de Ciências Exatas da ESALQ USP, o carinho, o respeito e a amizade.

Aos queridos amigos Andréia, Geneville e Glaucy, a amizade incondicional.

Às amigas de moradia, Katiere, Sheila, e Socorro, a grande amizade, o companheirismo e o carinho. 
Ao querido Romulo, o companheirismo e a ajuda na etapa final.

Aos preciosos colegas da pós-graduação, o incentivo, o companheirismo e a grande ajuda.

À CAPES, pela bolsa de estudos concedida. 


\section{SUMÁRIO}

Página

LISTA DE FIGURAS

viii

LISTA DE TABELAS IX

RESUMO - X

SUMMARY Xi

1 INTRODUÇÃO 1

2 REVISÃO DE LITERATURA

2.1 Análise de Sobrevivência . . . . . . . . . . . . . . 3

2.1.1 Função Densidade de Probabilidade . . . . . . . . . . . . 3

2.1.2 Função de Sobrevivência . . . . . . . . . . . . . . . 4

2.1.3 Função Risco ....................... 4

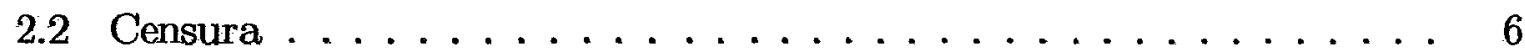

2.3 Estimação da Função de Sobrevivência . . . . . . . . . . . 8

2.3.1 Tabela de Vida ......................... 8

2.3.2 Estimador Produto Limite ou de Kaplan-Meier (K-M) . . . . . . . 9

2.4 Testes não-paramétricos para comparar duas funções de sobrevivência . . 10

2.4.1 Teste de Gehan ....................... 10

2.4 .2 Teste "Logrank" ........................... 12

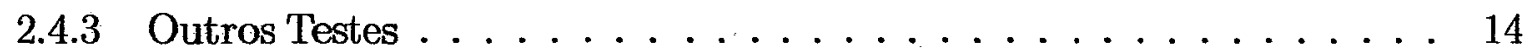

2.4.4 Teste de Friedman ...................... 15 
3 MATERTAL E MÉTODOS

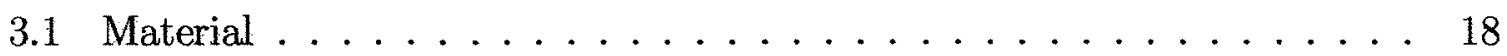

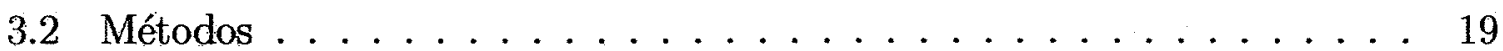

3.2 .1 Sobre os conjuntos de dados . . . . . . . . . . . . . 20

3.2 .2 Sobre os dados simulados . . . . . . . . . . . . . . 21

4 RESULTADOS E DISCUSSÃO 22

5 CONCLUSÕES $\quad$. $\quad 26$

REFERÊNCIAS BIBLIOGRÁFICAS $\quad 27$

$\begin{array}{lr}\text { APENDICES } & 29\end{array}$ 


\section{LISTA DE FIGURAS}

Página

$1 \quad$ Censura Tipo $1 \ldots \ldots \ldots \ldots \ldots \ldots \ldots \ldots \ldots$

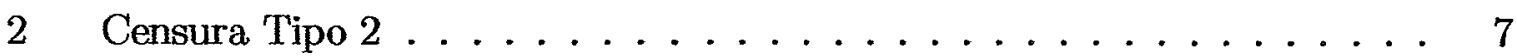

3 Censura Aleatória . . . . . . . . . . . . . . . 7

4 Curvas de Sobrevivência (Kaplan-Meier) para os dados de Hepatite Viral Aguda (Dados 1) . . . . . . . . . . . . . . . . . . . . . 22

5 Curvas de sobrevivência (Kaplan-Meier) para os dados de ratos (Dados

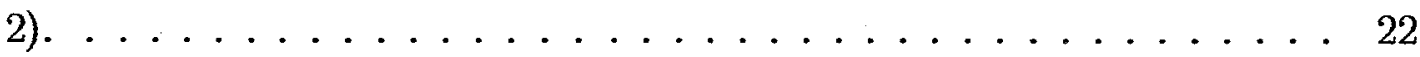

6 Curvas de sobrevivência (Kaplan-Meier) para pacientes submetidos a tratamentos para redução de tumor (Dados 3$). \ldots \ldots \ldots$. . . . . 23 


\section{LISTA DE TABELAS}

Página

1 Tempos de vida de pacientes com Hepatite Viral Aguda, submetidos a dois tratamentos. . . . . . . . . . . . . . . 40

2 Tempos de sobrevivência de ratos, submetidos a dois pré-tratamentos. . . 41

3 Tempos de sobrevivência de 12 pacientes com tumor no cérebro. . . . . . 42 


\title{
MÉTODOS DE COMPARAÇÃO DE CURVAS DE SOBREVIVÊNCIA
}

\author{
Autora: JANAÍNA PEREIRA \\ Orientadora: Prof $\underline{a}$ Dr $\underline{a}$ ROSELI APARECIDA LEANDRO
}

\section{RESUMO}

A análise de sobrevivência é uma das áreas da estatística que mais tem crescido nos últimos anos. Em Agronomia, é usada para analisar dados de tempo de vida de plantas, tempo de resistência de pragas, etc. Na Medicina, é ainda mais freqüente o seu uso, para a análise de tempo de vida (ou sobrevivência) de pacientes submetidos a diferentes tratamentos. Esta área da estatística necessita de métodos e procedimentos específicos para análise, pelo fato de serem considerados os tempos censurados. Os métodos desenvolvidos em análise de sobrevivência permitem que dois ou mais tratamentos sejam comparados por meio de suas curvas de sobrevivência utilizando-se procedimentos e testes específicos. Assim, o presente trabalho apresenta e discute conceitos, métodos e testes de comparação de curvas de sobrevivência, e propõe a utilização de um outro teste para comparar curvas

de sobrevivência: o Teste de Friedman. Os resultados obtidos na comparação dos testes demonstram que é possível a utilização do Teste de Friedman para comparar curvas de sobrevivência. 


\title{
COMPARING SURVIVAL CURVES
}

\author{
Author: JANAÍNA PEREIRA
}

Adviser: Prof $\underline{a}$ Dr $\stackrel{\underline{a}}{-}$ ROSELI APARECIDA LEANDRO

\section{SUMMARY}

Survival analysis plays a fundamental role in modeling events where is necessary to take in to account "censored data". In agricultural it can be used for analysing plants lifetime, in medicine it is used to analyse individuals lifetime submitted to differents treatments, etc. It is one of the branches of Statistics which has had a greater development in the last years. This work presents, discusses concepts, methods about survival analysis and propose the use of Friedman Test to do comparison of survival curves. 


\section{INTRODUÇÃO}

A análise de sobrevivência é um conjunto de procedimentos estatísticos para analisar dados que correspondem ao tempo até a ocorrência de um evento de interesse, tais como tempo até a falha de um componente ou a morte de um indivíduo (Kleinbaum, 1995). Esses estudos foram originalmente desenvolvidos para dados de mortalidade, explicando, portanto, o nome de sobrevivência que, segundo Allison (1995), é um tanto quanto inadequado por levar a uma visão restrita de suas potenciais aplicações.

Segundo Colosimo (2001), essa é uma das áreas que mais tem crescido nos últimos anos, não apenas pelo desenvolvimento e aprimoramento de métodos estatísticos, como também pelo número de aplicações.

Os métodos de análise de sobrevivência são extremamente úteis em diferentes áreas do conhecimento humano como por exemplo, na Engenharia, recebendo o nome de confiabilidade, em que os dados utilizados referem-se ao tempo até a falha de um componente ou produto; na Demografia, cujos eventos de interesse podem ser mortes, nascimentos, casamentos, divórcios ou migrações; na Agronomia, em que a variável resposta pode ser o tempo de vida das plantas. No entanto, segundo Chalita (1992), os experimentos na área de Ciências Agrárias ainda não são conduzidos a fim de serem analisados como dados de sobrevivência fato que pode ser devido à falta de informação dos pesquisadores nessa área.

Em análise de dados de sobrevivência, podem-se ressaltar duas características: a distribuição dos dados, em geral, é assimétrica positiva, o que impede a utilização de procedimentos clássicos que pressupõem a distribuição normal dos 
dados. A outra característica é a presença de censura, que significa a perda de informação de uma ou mais unidades experimentais no decorrer do experimento. A presença de censura é o que distingue a análise de sobrevivência de outros ramos da Estatística.

A comparação de tratamentos com dados de sobrevivência pode ser feita por meio de comparação de curvas de sobrevivência. Alguns métodos propostos para comparação de curvas de sobrevivência enfatizam determinadas partes da fụnção de sobrevivência de formas diferentes. Neste trabalho, propõe-se um novo método de comparação, através do teste de Friedman (Campos, 1983) em que são considerados tempos de interesse, previamente especificados pelo pesquisador como blocos, propiciando analisar as curvas de sobrevivência em toda sua extensão. 


\section{REVISÃO DE LITERATURA}

\subsection{Análise de Sobrevivência}

Em análise de sobrevivência a variável resposta é, geralmente, o tempo até a ocorrência de um evento de interesse. Este tempo é denominado tempo de falha, podendo ser o tempo até a morte de um paciente, submetido a um determinado tratamento, o tempo até a cura ou recidiva de uma doença. Aqui o interesse será estudar o tempo até a falha, ou seja, o tempo de sobrevivência. Para isso serão introduzidos alguns conceitos básicos.

\subsubsection{Função Densidade de Probabilidade}

O tempo de sobrevivência $T$ tem função densidade de probabilidade, $f(t)$, definida como a probabilidade de o indivíduo falhar no intervalo $[t, t+\Delta t]$ por unidade de tempo, que pode ser expressa por

$$
\begin{aligned}
f(t)= & \lim _{\Delta t \rightarrow 0^{+}} \frac{P(\text { indivíduo falhar em }[t, t+\Delta t])}{\Delta t} \\
& =\lim _{\Delta t \rightarrow 0^{+}} \frac{P(t \leq T \leq t+\Delta t)}{\Delta t} \\
& =\lim _{\Delta t \rightarrow 0^{+}} \frac{P(T \leq t+\Delta t)-P(T \leq t)}{\Delta t} \\
& =\lim _{\Delta t \rightarrow 0^{+}} \frac{F(t+\Delta t)-F(t)}{\Delta t}=\frac{d F(t)}{d t}
\end{aligned}
$$


em que $F(t)=P[T \leq t]$ é definida como sendo a função de distribuição acumulada de T. Tem-se ainda que:

$$
f(t) \geq 0 \quad \text { e } \quad \int_{0}^{\infty} f(t) d t=1
$$

o que caracteriza $f($.$) como uma função densidade de probabilidade.$

\subsubsection{Função de Sobrevivência}

A função de sobrevivência, denotada por $S(t)$, representa a probabilidade de um indivíduo não falhar até o tempo $t$, isto é,

$$
S(t)=P[T \geq t]=1-F(t)
$$

que é uma função monótona decrescente em que:

$$
S(0)=1 \quad \text { e } \quad \lim _{t \rightarrow \infty} S(t)=0
$$

$\mathrm{Na}$ prática, a função de sobrevivência pode ser estimada como a proporção de indivíduos que sobreviveram até o tempo t, isto é,

$$
\hat{S}(t)=\frac{\text { número de unidades que sobreviveram até o tempo t }}{\text { número total de unidades }}
$$

A função de sobrevivência é também conhecida como razão de sobrevivência acumulada e sua representação gráfica, recomendada por Berkson (1942), é chamada de curva de sobrevivência, que pode ser usada para encontrar qualquer percentil de interesse e também, como um primeiro elemento de comparação entre dois ou mais tratamentos.

\subsubsection{Função Risco}

A função risco, denotada por $h(t)$, especifica a razão de falha condicional. Esta função é definida como o limite da probabilidade de a unidade falhar 
entre os tempos $t$ e $t+\Delta t$, dạdo que sobreviveu até o tempo $t$, quando $\Delta t \rightarrow 0^{+}$, ou seja;

$$
\begin{aligned}
h(t) & =\lim _{\Delta t \rightarrow 0^{+}} \frac{P(t \leq T \leq t+\Delta t \mid T \geq t)}{\Delta t} \\
= & \lim _{\Delta t \rightarrow 0^{+}} \frac{P(t \leq T \leq t+\Delta t, T \geq t)}{\Delta t P(T \geq t)} \\
& =\lim _{\Delta t \rightarrow 0^{+}} \frac{P(t \leq T \leq t+\Delta t)}{\Delta t P(T \geq t)},
\end{aligned}
$$

pois o intervalo $[t, t+\Delta t]$ está contido no intervalo $[t, \infty)$. Assim,

$$
\begin{gathered}
h(t)=\lim _{\Delta t \rightarrow 0^{+}} \frac{F(t+\Delta t)-F(t)}{\Delta t S(t)}=\frac{f(t)}{S(t)} \\
=\frac{f(t)}{1-F(t)} .
\end{gathered}
$$

É possível relacionar as funções $f(t), S(t)$ e $h(t)$. Tem-se que:

$$
h(t)=\frac{f(t)}{S(t)}
$$

e sabe-se que

$$
f(t)=\frac{d F(t)}{d t}=\frac{d[1-S(t)]}{d t}=-S^{\prime}(t)
$$

Substituindo a equação (2) em (1), segue-se que:

$$
h(t)=\frac{-S^{\prime}(t)}{S(t)}=\frac{-d \log (S(t))}{d t} .
$$

Integrando no intervalo $[0, t]$ e usando $S(0)=1$ vê-se que:

$$
-\int_{0}^{t} h(x) d x=\log (S(t))
$$

ou,

$$
H(t)=-\log (S(t))
$$

ou ainda,

$$
S(t)=\exp [-H(t)]=\exp \left[-\int_{0}^{t} h(x) d x\right]
$$

Das equações (1) e (3), obtém-se:

$$
f(t)=h(t) \exp [-H(t)] .
$$




\subsection{Censura}

A principal característica de dados de sobrevivência é a presença de censura que ocorre quando ao final do estudo, nem todas as unidades falharam sendo importante considerar esses tempos nas análises. Segundo Bolfaríne et al. (1991), podem-se considerar três tipos de censuras:

\section{(a) Censura Tipo 1}

Ocorre quando o estudo é encerrado após um período pré-estabelecido de tempo. Por exemplo, fixa-se um tempo, ao final do qual, encerra-se o estudo, independente de as unidades falharem, ou não, de forma que se perde informação sobre determinadas unidades.

\section{(b) Censura Tipo 2}

Ocorre quando o estudo é encerrado após ter ocorrido o evento de interesse em um número pré-estabelecido de indivíduos. Portanto, encerra-se o estudo com as unidades que falharam e nada se pode afirmar a respeito das outras unidades.

\section{(c) Censura Aleatória}

Ocorre quando a unidade é retirada no decorrer do estudo sem ter ocorrido a falha. Por exemplo quando a unidade falha por uma razão diferente da estudada. Em ensaios clínicos, um fator que causa censura aleatória é a perda de segmento (loss-to-follow-up), ou seja, por alguma razão o paciente sai do estudo. 
Uma ilustração sobre os três tipos de censuras pode ser observada a seguir:

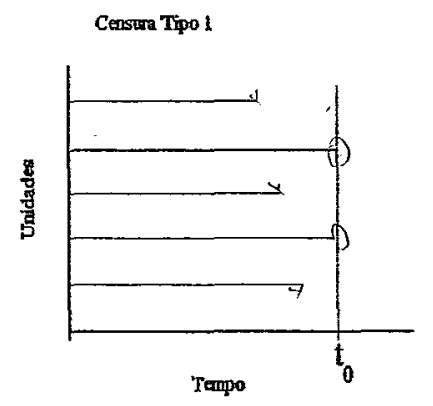

Figura 1 - Censura Tipo 1

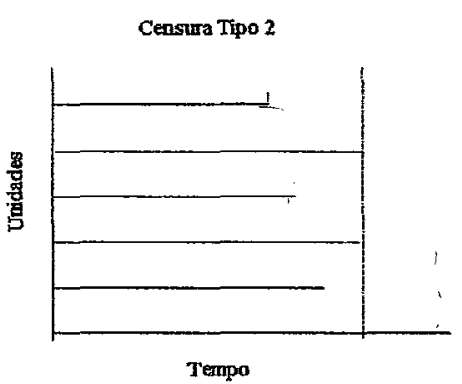

Figura 2 - Censura Tipo 2

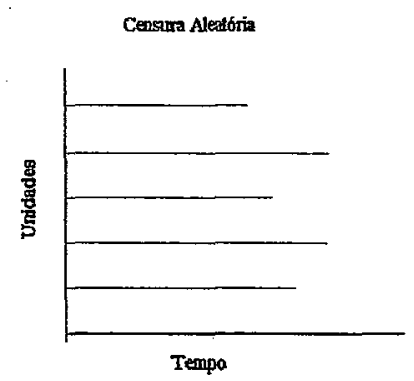

Figura 3 - Censura Aleatória 


\subsection{Estimação da Função de Sobrevivência}

A estimação da função de sobrevivência é o principal objetivo da Análise de Sobrevivência. Na ausência de censura, os dados observados podem ser analisados como experimentos comuns, submetendo-os a testes menos específicos, como o da análise de variância. Porém, na presença de censurą, a estimação da função de sobrevivência requer técnicas estatísticas especializadas para acomodar a informação contida nos dados. A observação censurada informa que o tempo até a falha é maior do que aquele em que a censura foi registrada.

Dois métodos de estimação não-paramétricos para a função de sobrevivência são bem conhecidos: o método de Tabela de Vida e Estimador do ProdutoLimite de Kaplan-Meier.

\subsubsection{Tabela de Vida}

A construção de uma tabela de vida consiste em dividir o período (tempo) de observações de $n$ indivíduos em $k+1$ intervalos definidos pelos seguintes pontos de corte: $t_{1}, t_{2}, \ldots, t_{k}$, isto é, $I_{i}=\left[t_{i-1}, t_{i}\right) ; i=1, \ldots, k+1$, em que $t_{0}=0$ e $t_{k+1}=+\infty$. Para cada intervalo $I_{i}=\left[t_{i-1}, t_{i}\right)$ calculam-se as estimativas das probabilidades condicionais de a falha ocorrer até $t_{i}$, dado que não ocorreu até $t_{i-1}$, ou seja,

$$
q_{i}=P\left(T \leq t_{i} \mid T \geq t_{i-1}\right)=\frac{P\left(t_{i-1} \leq T \leq t_{i}\right)}{P\left(T \geq t_{i-1}\right)}=\frac{F\left(t_{i}\right)-F\left(t_{i-1}\right)}{1-F\left(t_{i-1}\right)}
$$

e a probabilidade condicional de a falha não ocorrer até $t_{i}$, dado que não ocorreu até $t_{i-1}$ é dada por

$$
p_{i}=1-q_{i}=P\left(T \geq t_{i} \mid T \geq t_{i-1}\right)=\frac{S\left(t_{i}\right)}{S\left(t_{i-1}\right)} .
$$

Portanto, a função de sobrevivência em $t_{i}$, é dada por

$$
S\left(t_{i}\right)=P\left(T \geq t_{1} \mid T \geq t_{0}\right) P\left(T \geq t_{2} \mid T \geq t_{1}\right) \ldots P\left(T \geq t_{i} \mid T \geq t_{i-1}\right)
$$


$=p_{1} p_{2} \ldots p_{i}$

Desse modo, um estimador de $S\left(t_{k}\right)$ é dado por

$$
\hat{S}\left(t_{i}\right)=\hat{p}_{1} \hat{p}_{2} \ldots \hat{p}_{i}
$$

em que:

$\hat{p}_{i}=1-\hat{q}_{i}$ e $\hat{q}_{i}=\frac{d_{i}}{n_{i}-\frac{w_{i}}{2}}$

$d_{i}$ é o número de unidades que falharam no intervalo $I_{i}=\left[t_{i-1}, t_{i}\right)$;

$n_{i}$ é o número de unidades sob risco em $t_{i-1}$;

$w_{i}$ é o número de censuras no intervalo $I_{i}$.

Note que em $\hat{q}_{i}$, considera-se o valor $\frac{w_{i}}{2}$ indicando que as observações censuradas no intervalo $I_{i}$ são tratadas como se estivessem sob risco durante a metade do intervalo considerado.

\subsubsection{Estimador Produto Limite ou de Kaplan-Meier (K-M)}

Este estimador não-paramétrico para a função de sobrevivência, foi proposto por Kaplan \& Meier (1958) e é também chamado de Estimador ProdutoLimite. Bolfarine et al. (1991) comentam que este estimador pode ser visto como o caso limite dos estimadores da tabela de vida quando o número de partições no intervalo $[0, t]$ tende a infinito. Segundo Lee (1980), a principal diferença entre o estimador de Kaplan-Meier e o estimador tabela de vida é o conhecimento do tempo exato de falha enquanto que na tabela de vida, conhece-se apenas o intervalo em que ocorreu a falha. Assim, o estimador de Kaplan-Meier é um caso especial do estimador tabela de vida quando cada intervalo contém apenas uma observação. O estimador de Kaplan-Meier é obtido da seguinte forma: considere $n$ indivíduos e $k \leq n$ falhas distintas nos tempos $t_{1}<t_{2}<\ldots<t_{k}$. Ocasionalmente, pode ocorrer mais de uma falha no mesmo tempo, o que é chamado de empate. Sejam $d_{i}$ o número de falhas em $t_{i}$ e $n_{i}$ o número de observações sob risco (não falhou e não foi censurado) até o 
tempo $t_{i}$ (exclusive). Portanto, a função de sobrevivência será estimada por

$$
\hat{S}_{K M}(t)=\prod_{i \mid t_{i}<t}\left(\frac{n_{i}-d_{i}}{n_{i}}\right) .
$$

Para justificar a expressão (5), basta observar a decomposição de $S\left(t_{i}\right)$ feita em (4) usando o estimador tabela de vida:

$$
\hat{S}\left(t_{i}\right)=\hat{p}_{1} \hat{p}_{2} \ldots \hat{p}_{i}
$$

Estimam-se os $q_{i}^{\prime} s$ por $\frac{d_{i}}{n_{i}}, i=1,2, \ldots, k$. Kaplan \& Meier (1958) justificam que a expressão para (5) é o estimador de máxima verossimilhança de $S(t)$.

É necessário avaliar a precisão do estimador de Kaplan-Meier para se construírem intervalos de confiança e se testarem hipóteses para $S(t)$. A expressão para a variância assintótica de $\hat{S}(t)$ (Lee, 1980) é dada por:

$$
\operatorname{Var}(\hat{S}(t))=\hat{S}(t)^{2} \sum_{i \mid t_{i}<t} \frac{d_{i}}{n_{i}\left(n_{i}-d_{i}\right)} .
$$

\subsection{Testes não-paramétricos para comparar duas funções de sobrevivência}

\subsubsection{Teste de Gehan}

Seja $X_{i}=\min \left(T_{i}, L_{i}\right), i=1,2, \ldots, n_{1}$, uma amostra aleatória das unidades da população que foram submetidas ao tratamento 1 , em que se supõe $T_{i}$ como o tempo de falha com função de distribuição $F_{1}$ e $L_{i}$ o tempo de censura com função de distribuição $G_{1}$. Seja $Y_{j}=\min \left(D_{j}, C_{j}\right), j=1,2, \ldots, n_{2}$, uma amostra aleatória das unidades da população que foram submetidas ao tratamento 2 , em que $D_{j}$ representa o tempo de falha com função de distribuição $F_{2}$, e $C_{j}$ representa o tempo de censura com função de distribuição $G_{2}$. A fim de comparar a diferença entre os tratamentos 1 e 2, Gehan (1965) propõe testar as hipóteses: 
$H_{0}: F_{1}(t)=F_{2}(t)$ (os tratamentos não diferem entre si)

versus

$H_{a}: F_{1}(t)<F_{2}(t)$ (o tratamento 1 é mais eficiente do que o tratamento 2)

ou

$H_{0}: S_{1}(t)=S_{2}(t)$

versus

$H_{a}: S_{1}(t)>S_{2}(t)$

em que $S_{1}(t)$ e $S_{2}(t)$ são, respectivamente, as funções de sobrevivência das populações submetidas aos tratamentos 1 e 2 .

Gehan compara cada observação da amostra 1 com cada observação da amostra 2, definindo:

$$
U_{i j}=\left\{\begin{array}{rll}
-1 & \text { se } & \left(x_{i}<y_{j}, \delta_{i}=1\right) \text { ou }\left(x_{i}=y_{j}, \delta_{i}=1, \epsilon_{j}=0\right) \\
1 & \text { se } & \left(x_{i}>y_{j}, \epsilon_{j}=1\right) \text { ou }\left(x_{i}=y_{j}, \delta_{i}=0, \epsilon_{j}=1\right) \\
0 & & \text { caso contrário }
\end{array}\right.
$$

em que $\delta_{i}$ é o indicador de censura da população submetida ao tratamento 1 e $\epsilon_{j}$ é o indicador de censura da população submetida ao tratamento 2 e a estatística,

$$
W=\sum_{j=1}^{n_{2}} \sum_{i=1}^{n_{1}} U_{i j}
$$

em que a soma é sobre toda comparação $n_{1} n_{2} \cdot{ }^{\prime} \mathrm{O}$ exemplo ilustrativo 1 (Apêndice 1) descreve o cálculo do valor de $W$.

Segundo Gehan, se a hipótese $H_{0}$ e verdadeira pode-se mostrar que $W$ tem uma distribuição assintoticamente normal com média zero. Para se obter a variância de $W$, todas as observações são arranjadas e dispostas em ordem crescente, a partir do primeiro tempo de falha, ou seja, o primeiro tempo de falha recebe posto 1, o segundo, posto 2, e assim, sucessivamente, até o último tempo de falha. Dessa ordenação, dividem-se as observações em dois grupos: $m_{i} \geq 1$, o número de observações que falham no posto $i$ e $l_{i}$ o número de observações censuradas com 
valores maiores do que as observações não censuradas de posto $i$, mas menores do que as observações de posto $(i+1)$. Sob $H_{0}$, a variância de $W$ é:

$$
\begin{aligned}
\operatorname{var}(W)= & \frac{n_{1} n_{2}}{\left(n_{1}+n_{2}\right)\left(n_{1}+n_{2}-1\right)}\left\{\sum_{i=1}^{k} m_{i} M_{i-1}\left(M_{i-1}+1\right)+\sum_{i=1}^{k} l_{i} M_{i}\left(M_{i}+1\right)\right. \\
& \left.+\sum_{i=1}^{k} m_{i}\left(n_{1}+n_{2}-M_{i}-L_{i-1}\right)\left(n_{1}+n_{2}-3 M_{i-1}-m_{i}-L_{i-1}-1\right)\right\}
\end{aligned}
$$

em que $k$ é o número de observações distintas não censuradas, e

$$
M_{j}=\sum_{i=1}^{j} m_{i} ; \quad M_{0}=0 ; \quad L_{j}=\sum_{i=1}^{j} l_{i} ; \quad L_{0}=0 .
$$

O exemplo ilustrativo 2 (Apêndice 1) descreve como obter $\operatorname{Var}(W)$.

Se não há empates ou falhas, isto é, $m_{1}=m_{2}=\ldots=m_{k}=1 \mathrm{e}$ $k=n_{1}+n_{2}$, a equação da variância de $W$ fica:

$$
\operatorname{var}(W)=\frac{1}{3} n_{1}+n_{2}\left(n_{1}+n_{2}+1\right)
$$

Se não há empates e todas as observações são censuradas após $\left(r_{1}+r_{2}\right)$ falhas, isto é, $m_{1}=m_{2}=\ldots=m_{k}=1, l_{1}=l_{2}=\ldots=l_{k-1}=0, l_{k}=n_{1}-r_{1}+n_{2}-r_{2}$ e $k=r_{1}+r_{2}$, tem-se

$$
\begin{aligned}
\operatorname{var}(W)= & \frac{\left(n_{1} n_{2}\right)\left(r_{1}+r_{2}\right)}{\left(n_{1}+n_{2}\right)\left(n_{1}+n_{2}-1\right)}\left\{\left(n_{1}+n_{2}\right)\left(n_{1}-r_{1}+n_{2}-r_{2}\right)\right. \\
& \left.+\frac{1}{3}\left[\left(r_{1}+r_{2}\right)^{2}-1\right]\right\} .
\end{aligned}
$$

\subsubsection{Teste "Logrank"}

O Teste "logrank" é o mais usado em análise de sobrevivência. Segundo Collet (1994), o nome "logrank" foi devido ao fato de que a estatística do teste também pode ser originada dos postos dos tempos de sobrevivência nos dois grupos.

O Teste "logrank" resultou dos trabalhos de Mantel \& Haenzel (1959) e Mantel (1966). 
Suponha que haja $k$ tempos de falha distintos $t_{(1)}, t_{(2)}, \ldots, t_{(k)}$, na amostra formada pela combinação dos dois grupos e que no tempo $t_{(j)}, m_{1 j}$ indivíduos no grupo 1 e $m_{2 j}$ indivíduos no grupo 2 falham, $j=1,2, \ldots, k$. Sejam $n_{1 j}$ e $n_{2 j}$ os números de indivíduos sob risco em um tempo imediatamente inferior a $t_{(j)}$, nos grupos $1 \mathrm{e} 2$, respectivamente e, $n_{j}=n_{1 j}+n_{2 j}$. As hipóteses a serem testadas são:

$H_{0}$ : igualdade entre os tratamentos;

versus

$H_{a}$ : diferença entre os tratamentos.

A estatística do teste é:

$$
\frac{\sum_{j=1}^{k}\left(m_{i j}-e_{i j}\right)^{2}}{\operatorname{Var}(D)}
$$

em que

$$
e_{i j}=\frac{n_{i j}}{n_{j}}\left(m_{1 j}+m_{2 j}\right)
$$

e

$$
\operatorname{Var}(D)=\sum_{j=1}^{k} \frac{n_{1 j} n_{2 j}\left(m_{1 j}+m_{2 j}\right)\left(n_{j}-m_{1 j}-m_{2 j}\right)}{n_{j}^{2}\left(n_{j}-1\right)} .
$$

Compara-se então, o valor da estatística com o valor tabelado de uma $\chi_{1}^{2}$ \& rejeita-se $H_{0}$ se o valor calculado for superior ao valor tabelado.

Para comparar mais de dois tratamentos, por exemplo, $R$ tratamentos observa-se que:

$n_{i j}$ é o número de indivíduos em risco no i-ésimo tratamento e j-ésimo tempo;

$m_{i j}$ é o número de falhas ocorridas no i-ésimo tratamento e j-ésimo tempo;

$e_{i j}=\frac{n_{i j}}{\sum_{i=1}^{R} n_{i j}}\left(\sum_{i=1}^{R} m_{i j}\right)$;

$O_{i}-E_{i}=\sum_{j=1}^{k}\left(m_{i j}-e_{i j}\right)$

$d=\left(O_{1}-E_{1}, O_{2}-E_{2}, \ldots, O_{R-1}-E_{R-1}\right)$

$V=\left(v_{i l}\right)^{\prime}$ é a matriz de variâncias e covariâncias $l=1,2, \ldots, R-1$, 
$v_{i i}=\widehat{\operatorname{Var}}\left(O_{i}-E_{i}\right) \mathrm{e}$

$v_{i l}=\widehat{\operatorname{Cov}}\left(O_{i}-E_{i}, O_{l}-E_{l}\right)=\sum_{j=1}^{k} \frac{-n_{i j} n_{l j} m_{j}\left(n_{j}-m_{j}\right)}{n_{j}^{2}\left(n_{j}-1\right)}$.

A estatística do teste será então:

$$
d^{\prime} V^{-1} d
$$

e deverá ser comparada com o valor tabelado de uma $\chi_{R-1}^{2}, H_{0}$ será rejeitada se o valor calculado for superior ao valor tabelado.

\subsubsection{Outros Testes}

Em Colosimo (2001), outros testes não-paramétricos foram apresentados para comparar funções de sobrevivência. Para se compararem duas funções de sobrevivência, a forma geral (6) inclui os testes mais importantes na literatura e generaliza a estatística de "logrank" em ,

$$
U=\sum_{i=1}^{R}\left[\frac{\left[\sum_{j=1}^{k} u_{j}\left(m_{i j}-e_{i j}\right)\right]^{2}}{E_{i}}\right]
$$

em que

$$
E_{i}=\sum_{j=1}^{k} u_{i j}^{2} e_{i j}
$$

sendo que os $u_{j}^{\prime} s$ são pesos que especificam os testes.

Sob a hipótese nula que as funções de sobrevivência são iguais, a estatística $U$ tem distribuição $\chi_{1}^{2}$, para grandes amostras. O teste "logrank" é obtido quando se toma $u_{j}=1, j=1, \ldots, k$ : Outro teste bastante utilizado na prática é o Teste de Wilcoxon obtido quando se toma $u_{j}=n_{j}$. Este teste foi adaptado para dados censurados a partir do conhecido teste não-paramétrico de Wilcoxon (Gehan, 1965; Breslow, 1970). O Teste de Tarone \& Ware (1974) propõe peso $u_{j}=\sqrt{n_{j}}$, que fica entre os pesos do "logrank" e de Wilcoxon. 
Outra alternativa, apresentada em Lee (1980), é o Teste de Peto, em que, se ordenam os tempos de sobrevivência dos dois tratamentos em uma única amostra e obtém-se o "estimador-conjunto" da função de sobrevivência pelo método de Kaplan-Meier. A partir daí, obtém-se a seguinte estatística:

$$
\frac{I}{\sqrt{\operatorname{Var(P)}}}
$$

em que $I$ é a soma dos escores de um grupo (tratamento), isto é,

$$
I=\sum_{j=1}^{n_{i}} u_{j}
$$

em que:

$n_{i}=$ número de indivíduos submetidos ao tratamento $i$;

$u_{j}$ é obtido a partir do "estimador-conjunto", ou seja:

$u_{j}=S\left(t_{j-1}\right)+S\left(t_{j}\right)-1$, se o tempo observado é tempo de falha;

$u_{j}=S\left(t_{j^{\prime}}\right)-1$, se o tempo observado é tempo de censura, em que $j^{\prime}$ é o tempo de falha imediatamente anterior ao tempo de censura;

$S\left(t_{0}\right)=1$.

$$
\widehat{\operatorname{Var}(P)}=\left(\sum_{j=1}^{k} \frac{m_{j}\left(n_{j}-m_{j}\right)}{n_{j}}\right) \frac{n_{1} n_{2}}{n_{j}\left(n_{j}-1\right)}
$$

em que $m_{j}$ é o número total de unidades que falharam no tempo $j$.

\subsubsection{Teste de Friedman}

O Teste de Friedman (Campos, 1983) é usualmente aplicado em experimentos em blocos, quando as condições de normalidade dos dados e homogeneidade de variâncias não são satisfeitas. As pressuposições para a aplicação do teste são:

a) os blocos são independentes;

b) as populações submetidas aos $d$ tratamentos são semelhantes. 
As hipóteses a serem testadas:

$H_{0}: t_{1}=t_{2}=\ldots=t_{d}$

versus

$H_{a}: t_{i} \neq t_{i^{\prime}}$, para algum $i \neq i^{\prime}, i, i^{\prime} \in\{1, \ldots, d\}$.

Dentro de cada bloco procede-se à classificação conjunta das $d$ observações, dando posto 1 à menor e posto $d$ à maior delas. Assim, $R_{i j}$ corresponde ao posto do i-ésimo tratamento no j-ésimo bloco. Considerando a não ocorrência de empates dentro do mesmo bloco tem-se que o vetor de postos atribuídos aos $d$ tratamentos dentro do bloco $j,\left\{R_{1 j}, R_{2 j}, \ldots, R_{d j}\right\}$, é alguma permutação dos inteiros $1,2, \ldots, d$. Considerando os blocos independentes e sob $H_{0}$, tem-se que, $P\left(R_{i j}=r\right)=\frac{1}{d}$.

$$
P\left(R_{i j}=r, R_{i^{\prime} j}=s\right)=\frac{1}{d(d+1)}, i \neq i^{\prime}
$$

sendo

$$
E\left[R_{i j}\right]=\frac{d+1}{2} ; \sigma^{2}\left(R_{i j}\right)=\frac{d^{2}-1}{12} ; \operatorname{Cov}\left(R_{i j}, R_{i^{\prime} j}\right)=\frac{d+1}{12}, i \neq i^{\prime} .
$$

Sob $H_{0}$, todas as $d$ ! possíveis ordenações são igualmente prováveis e as atribuições de postos nos diferentes blocos são independentes. Assim, para $b$ blocos:

$$
P_{H_{0}}\left(R_{11}=r_{11}, \ldots, R_{d 1}=r_{d 1}, \ldots, R_{1 b}=r_{1 b}, \ldots, R_{d b}=r_{d b}\right)=\frac{1}{(d !)^{b}} .
$$

Para se testar $H_{0}$, utiliza-se a seguinte estatística:

$$
U=\frac{12}{d b(d+1)} \sum_{i=1}^{d} R_{i}^{2}-3 b(d+1)
$$

em que $R_{i}$ é a soma das ordens atribuídas aos valores estimados da função de sobrevivência dos $d$ tratamentos nos $b$ blocos. A hipótese nula será rejeitada, ao nível $\alpha$ de significância, se $U$ for maior ou igual ao valor tabelado $U_{t}$, em que $P_{H_{0}}\left(U \geq U_{t}\right)=\alpha$. Os valores de $U_{t}$ para $d \leq 5$, são encontrados em tabelas (Campos, 1983). Para $d>5$ deve-se utilizar a aproximação para grandes amostras, $\chi_{d-1}^{2}$. 
No caso de empates entre as observações de um mesmo bloco, utiliza-se a média dos postos. Além disso, é necessário aplicar uma correção ao valor de $U$ :

$$
C=1-\frac{\sum_{j=1}^{b} D_{j}}{b d\left(d^{2}-1\right)}
$$

em que $D_{j}=\sum_{i=1}^{d} c_{i j}^{3}-d, c_{i j}$ é o número de observações empatadas no tratamento $i$ e no bloco $j$, ficando a nova expressão da estatística dada por:

$$
U^{\prime}=\frac{U}{C}
$$

Novamente, compara-se $U^{\prime}$ com valor tabelado, rejeitando-se a hipótese nula se $U^{\prime} \geq U_{t}$. 


\section{MATERIAL E MÉTODOS}

\subsection{Material}

Visando avaliar os testes de comparação de curvas de sobrevivência, foram utilizados três conjuntos de dados apresentados na literatura e outros conjuntos de dados simulados utilizando um programa de simulação (Programa 2 - Apêndice 2) implementado no pacote estatístico R (Venables \& Smith, 1992).

Dados 1: Os dados apresentados na Tabela 1 (Apêndice 3) referem-se a um estudo realizado para se estudar o efeito de terapia com esteróide no tratamento de hepatite viral aguda (Colosimo, 2001). Vinte e nove pacientes com hepatite viral aguda foram aleatorizados para receber um placebo(1) ou o tratamento com esteróide(2). O tratamento foi acompanhado durante 16 semanas ou até a morte do paciente ou até a perda de acompanhamento.

Dados 2: Os dados apresentados na Tabela 2 (Apêndice 3), referem-se a um estudo realizado com quarenta ratos tratados com "carcinogen DMBA", a fim de observar o aparecimento ou não de câncer (Kalbfleisch \& Prentice, 1980). As doses do medicamento foram iguais nos dois grupos, e para distinguí-los, aplicou-se um pré-tratamento (não especificado) em cada um dos grupos.

Dados 3: Na Tabela 3 (Apêndice 3), são apresentados os dados (Lee, 1980) de doze pacientes que apresentavam tumor no cérebro. Os pacientes foram aleatorizados para receber radioterapia(1) ou radioterapia com quimioterapia(2). Um ano após o início do estudo, o tempo, em semanas, foi analisado. 
Dados Simulados: Para a simulação dos dados, foi utilizado o Programa 2 (Apêndice 2), implementado no pacote estatístico R. Nesse programa, foram gerados conjuntos de dados $Y$ com diferentes tamanhos amostrais $\left(n_{1}, n_{2}, \ldots\right)$, sendo que cada $y_{i} \in Y$ é uma terna $\left(t_{i}, c_{i}, t r_{i}\right)$ em que:

$t_{i}$ é tempo de sobrevivência do indivíduo $i$, em que $t_{i} \in(0, \infty)$;

$c_{i}$ é censura, sendo que

$$
c_{i}= \begin{cases}0 & \text { se o tempo não for censurado } \\ 1 & \text { caso contrário }\end{cases}
$$

$t r_{i}$ é tratamento ao qual o indivíduo $i$ foi submetido, que poderá ser:

$$
t r_{i}= \begin{cases}1 & \text { se indivíduo i foi submetido ao tratamento } 1 \\ 2 & \text { se indivíduo i foi submetido ao tratamento } 2\end{cases}
$$

com $i \in\{0, \ldots, n\}$.

\subsection{Métodos}

Os métodos de comparação de curvas de sobrevivência apresentados, em geral, enfatizam determinadas partes da função de sobrevivência: por exemplo, o Teste "Logrank" enfatiza a cauda da função de sobrevivência enquanto que o Teste de Peto e o Teste de Wilcoxon enfatizam o início da função de sobrevivência.

Neste trabalho propõe-se a utilização do Teste de Friedman em que se considerarão como blocos, tempos específicos pré-determinados pelo pesquisador, os quais propiciarão a comparação de curvas de sobrevivência em toda sua extensão.

As conclusões usando o Teste de Friedman, são, em geral, baseadas em tabelas existentes na literatura. Tais tabelas, freqüentemente, não fornecem os valores críticos para qualquer número de tratamentos e repetições ou blocos. O que se faz é considerar distribuições assintóticas para a obtenção dos valores, as quais podem conduzir a resultados pouco confiáveis. 
Outro problema é a ocorrência de observações empatadas. Quando isso ocorre é necessário considerar a configuração apresentada para a determinação do valor crítico do teste, ou seja, é necessária uma tabela específica para essa configuração, a fim de obter valores críticos corretos para o teste aplicado.

Para solucionar os problemas apresentados, foram utilizados os programas desenvolvidos por Pontes (2000), que são baseados em testes de permutação para encontrar os valores nominais corretos na aplicação do Teste de Friedman.

Para a aplicação do Teste de Friedman aos conjuntos de dados apresentados na literatura, os blocos foram escolhidos de acordo com cada conjunto de dados, e então submetidos ao programa desenvolvido por Pontes (2000).

Os dados da literatura foram submetidos aos testes de "Logrank", Peto, Wilcoxon e Friedman. Para obtenção das estatísticas dos testes de "Logrank" e Wilcoxon, juntamente com seus respectivos valores nominais, foi utilizado o Programa 1 (Apêndice 2), executado no pacote estatístico SAS. Além das estatísticas e dos valores nominais, o Programa 1 também apresenta as curvas de sobrevivência dos conjuntos de dados.

\subsubsection{Sobre os conjuntos de dados}

Dados 1: Para o conjunto de dados 1, os tempo específicos considerado como blocos para a aplicação do teste de Friedman foram: 1, 3, 5, 7, 9, 11, 13, 15 e 17 semanas. Portanto foram nove blocos, nos quais foram comparadas as estimativas de sobrevivência dos indivíduos submetidos a tratamento com placebo e tratamento com esteróide.

Dados 2: Os tempos específicos considerados como blocos pära o conjunto de dados 2, visando a aplicação do teste de Friedman, foram: 142, 155, 168, 181, 194, 207, 220, 233, 247, 261, 275, 289, 303, 317, 331 e 345. Portanto, considerouse 16 blocos, em que comparou-se as estimativas de sobrevivência dos ratos submetidos ao tratamento com "carcinogem DMBA". O objetivo de se comparar os dois grupos de ratos dedicava-se exclusivamente a concluir sobre um 
pré-tratamento aplicado a um dos grupos.

Dados 3: Para o conjunto de dados 3, os tempos específicos considerados como blocos, para o teste de Friedman, foram: 10, 14, 18, 22, 26, 30, 34, 38, 42 semanas.

\subsubsection{Sobre os dados simulados}

Foram gerados 500 conjuntos de dados para cada um dos diferentes tamanhos amostrais, com a finalidade de definir o número de tempos específicos a ser considerado em cada caso. Estes tempos específicos são utilizados, no teste de Friedman, como número de "blocos". Em relação aos tempos específicos para cada tamanho de amostras simuladas, optou-se por escolher, o número de tempos específicos que fornecesse maior concordância com os resultados obtidos entre os testes: "Logrank", Peto e Friedman. 


\section{RESULTADOS E DISCUSSÃO}

Os gráficos das curvas de sobrevivência para cada conjunto de dados são mostrados a seguir:

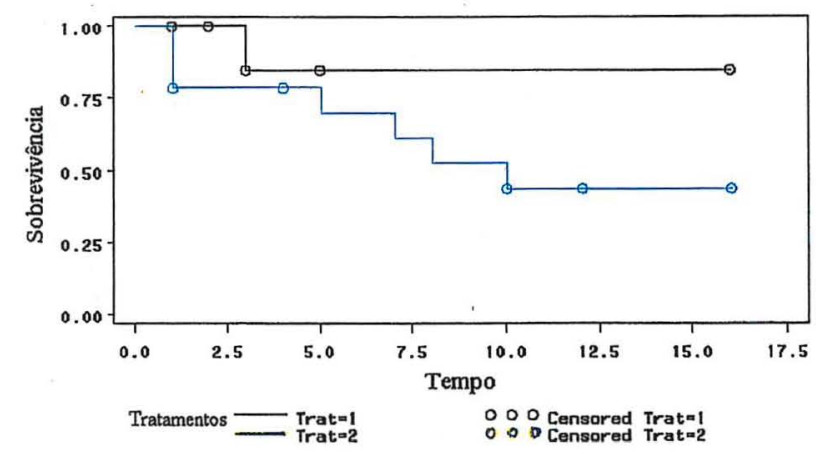

Figura 4 - Curvas de Sobrevivência (Kaplan-Meier) para os dados de Hepatite Viral Aguda (Dados 1).

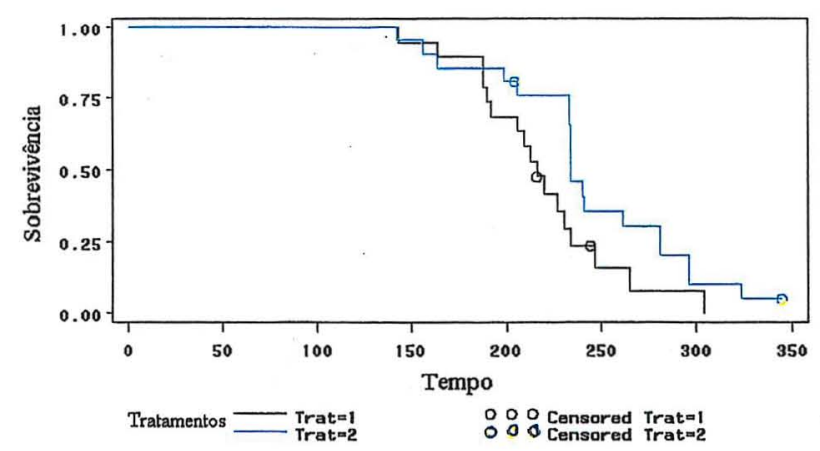

Figura 5 - Curvas de sobrevivência (Kaplan-Meier) para os dados de ratos (Dados 2). 


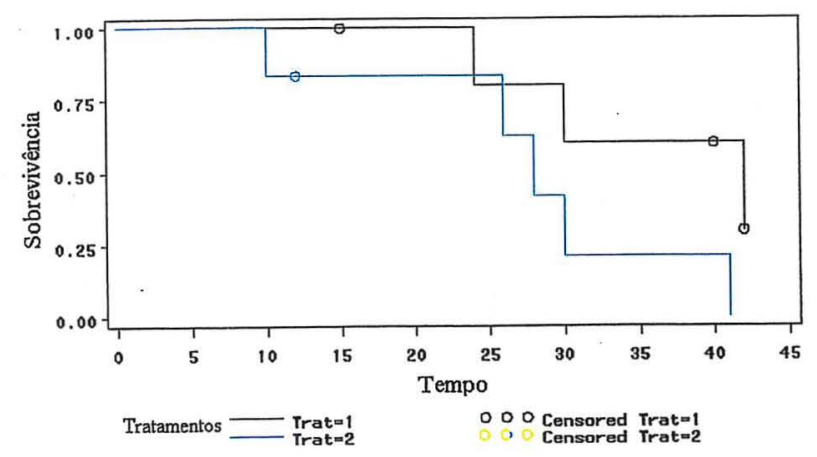

Figura 6 - Curvas de sobrevivência (Kaplan-Meier) para pacientes submetidos a tratamentos para redução de tumor (Dados 3).

Observando as Figuras 4, 5 e 6, referentes aos conjuntos de dados 1, 2 e 3, respectivamente, pode-se observar uma aparente diferença entre os tratamentos, esta diferença não é acusada nos testes comumente utilizados. Nas Figuras 4 e 6 , um tratamento supera o outro praticamente em toda a extensão da curva de sobrevivência. O Teste de Friedman foi aplicado, de forma a comparar toda a extensão da curva de sobrevivência, e não somente onde ocorrem as falhas ou censuras. Assim, pode-se observar o tempo que um tratamento permaneceu superior ao outro, diferentemente dos demais testes, que se prendem aos tempos em que ocorrem as falhas ou censuras.

O Quadro 1 apresenta o resultado dos valores nominais dos testes aplicados aos três conjuntos de dados.

\begin{tabular}{|c|c|c|c|c|}
\hline Conjuntos & "Log-rank" & Wilcoxon & Peto & Friedman \\
\hline Dados 1 & 0,0555 & 0,0741 & 0,0633 & 0,0078 \\
Dados 2 & 0,0772 & 0,1035 & 0,1035 & 0,0039 \\
Dados 3 & 0,0896 & 0,1590 & 0,1465 & 0,0039 \\
\hline
\end{tabular}

Quadro 1 - Valores Nominais obtidos para os conjuntos de dados.

Para obtenção dos resultados referentes aos testes de "Logrank" e Wilcoxon, apresentados no Quadro 1, foi utilizado, o Programa 1 (Apêndice 2), 
implementado no pacote estatístico SAS. Os resultados referentes ao Teste de Peto foram obtidos através do Programa 2 (Apêndice 2), implementado no pacote estatístico R. Os resultados referentes ao Teste de Friedman, obtidos com o programa desenvolvido por Pontes (2000), detectaram diferenças significativas entre os tratamentos.

Os conjuntos de dados simulados, ao serem submetidos simultaneamente aos testes de "Logrank", Peto e Friedman, forneceram valores nominais muito próximos, ou seja, na maioria dos casos, oṣ testes de "Logrank", Peto e Friedman indicam rejeição de $H_{0}$, ou os três indicam a não rejeição de $H_{0}$. Em casos esporádicos, o resultado do Teste de Friedman coincide com apenas um dos resultados dos outros testes, e não com os dois. E há também uma discordância de resultados, em alguns casos.

O Quadro 2 apresenta de forma resumida os resultados obtidos com as diversas simulações.

\begin{tabular}{|c|c|c|}
\hline Tamanho amostral & Número de Tempos Específicos & Concordâncias \\
\hline$n=16$ & 4 & $80 \%$ \\
$n=16$ & 5 & $70 \%$ \\
$n=16$ & 6 & $65 \%$ \\
$n=20$ & 4 & $75 \%$ \\
$n=20$ & 5 & $60 \%$ \\
$n=20$ & 6 & $70 \%$ \\
$n=36$ & 12 & $65 \%$ \\
$n=36$ & 13 & $70 \%$ \\
$n=36$ & 14 & $70 \%$ \\
$n=50$ & 14 & $70 \%$ \\
$n=50$ & 15 & $80 \%$ \\
$n=50$ & 16 & $75 \%$ \\
$n=100$ & 28 & $97 \%$ \\
$n=100$ & 29 & $98 \%$ \\
$n=100$ & 30 & $99 \%$ \\
\hline
\end{tabular}

Quadro 2 - Resultados obtidos através das simulações.

Observando o Quadro 2, verifica-se que considerando $n=16$, e 4 tem- 
de resultados em $80 \%$ dos casos, ou seja, havendo concordância com um dos testes: "Logrank" ou Peto, considerarse equivalência de resultados.

Para o caso de amostras de tamanho $n=20$, considerando-se 4 tempos específicos, pode-se obter $75 \%$ de concordâncias entre os resultados dos testes. Também foram considerados mais que 4 e menos que 4 tempos específicos, porém, os maiores índices de concordâncias foram obtidos considerando 4 tempos específicos.

O mesmo procedimento foi adotado com os outros tamanhos amostrais e diferentes números de tempos específicos.

Analisando os conjuntos de dados simulados, quando os testes são aplicados aos conjuntos de dados de tamanho $n=100$, os três testes concordam na grande maioria dos casos. Neste caso, pode-se observar que o Teste de Friedman, quando submetido a um grande número de dados, rejeita $H_{0}$ em praticamente $100 \%$ dos casos. Essa rejeição dá-se devido ao fato de serem considerados muitos tempos específicos, ocasionado um valor nominal de tamanho bem reduzido. 


\section{CONCLUSÕES}

De acordo com a metodologia desenvolvida e com as análises consideradas, pode-se concluir que:

- o Teste de Friedman pode ser usado para comparar duas curvas de sobrevivência;

- há uma grande dependência entre os resultados obtidos e o número de blocos escolhidos na aplicação do Teste de Friedman para comparar duas curvas de sobrevivência.

- ao analisar os tempos de sobrevivência equidistantes na curva de sobrevivência, o Teste de Friedman analisa toda a extensão da curva de sobrevivência, por igual, e não somente nos tempos observados, em que ocorreram falhas ou censuras. Assim, pode-se analisar durante quanto tempo um tratamento se manteve superior a outro, no decorrer do experimento.

Como sugestão para a continuidade deste estudo, aperfeiçoar o programa construído para simular dados, possibilitando comparar mais de dois tratamentos. 


\section{REFERÊNCIAS BIBLIOGRÁFICAS}

ALLISON, P. D. Survival analysis using the SAS system: a pratical guide. Cary: SAS Institute, 1995. 292p.

BERKSON, J. The calculation of survival rates in carcinoma and other malignant lesion of the stomach. Philadelphia: W. B. Sauders, 1942. 120p.

BOLFARINE, H.; RODRIGUES, J.; ACHCAR, J.A. Análise de sobrevivência. Rio de Janeiro: Instituto de Matemática da Universidade Federal do Rio de Janeiro / Associação brasileira de Estatística , 1991. 112p.

BRESLOW, N. Generalized Kruskal-Wallis for comparing K samples subject to unequal patterns of censorship. Biometrika, v.57, p.579-594, 1970.

CAMPOS, H. Estatística experimental não-paramétrica. Piracicaba: ESALQ, 1983. 349p.

CHALITA, L. V. A. S. Inferência paramétrica e não-paramétrica em análise de sobrevivência. Piracicaba, 1992. 96p. Dissertação (Mestrado)- Escola Superior de Agricultura "Luiz de Queiroz", Universidade de São Paulo.

COLLETT, D. Modelling survival data in medical research. London: Chapman \& Hall, 1994. 347p.

COLOSIMO, E. A. Análise de sobrevivência aplicada. Piracicaba: ESALQ / Departamento de Ciências Exatas, 2001. 145p.

GEHAN, E. A. A Generalized Wilcoxon test for comparing arbitraly singlycensured samples. Biometrika, v.52, p.203-223, 1965. 
KALBFLEISCH, J. D.; PRENTICE, R.L. The statistical analysis of failure time data. New York: John Wiley, 1980. 321p.

KAPLAN, E. L.; MEIER, P. Nonparametric estimation from incomplete observations. Journal of the American Statistical Association, v.53, p.457$481,1958$.

KLEINBAUM, D. G. Survival analysis: a self-learning text. New York: Springer-Verlag, 1995. 324p.

LEE, E. T.Statistical methods for survival data analysis. Belmont: Lifetime Learning Publ., 1980. 557p.

MANTEL, N. Evaluation of survival data and two new rank order statistics arising in its consideration. Cancer Chemotherapy Reports, v.50, p.163-170, 1966.

MANTEL, N.; HAENSZEL, W. Statistical aspects of the analisys of data from retrospective studies of disease. Journal of the National Cancer Institute, v.22, p.719-748, 1959 .

PONTES, A.C.F. Obtenção dos níveis de significância para os testes de KruskalWallis, Friedman e comparações múltiplas não-paramétricas. Piracicaba, 2000. 156p. Dissertação (Mestrado)- Escola Superior de Agricultura "Luiz de Queiroz", Universidade de São Paulo.

TARONE, R. E.; WARE, J. H. On distribution function with arbitraly grouped, censored and truncated data with doubly censored data. Journal of the American Statistical Association, v.69, p.169-173, 1974.

VENABLES, W. N.; SMITH, D. M. An introduction to R: Notes on R: a programming environment for data analysis and graphics. s.l.:s.ed.,1992. 1v. 
APÊNDICES 
Apêndice 1

Exemplo Ilustrativo 1

Consideram-se os tempos de sobrevivência dos pacientes de Hepatite Viral Aguda (Colosimo, 2001), para ilustrar a obtenção das estatísticas para o Teste de Gehan (+indica censura):

- Grupo controle (15 pacientes): $1+, 2+, 3,3,3+, 5+, 5+, 16+, 16+, 16+, 16+$, $16+, 16+, 16+, 16+$.

- Grupo Esteóide (14 pacientes): 1, 1, 1, 1+, 4+, 5, 7, 8, 10, 10+, 12+, 16+, $16+, 16+$.

Para a obtenção do valor de W para o Teste de Gehan, cada tempo de sobrevivência de um tratamento é comparado com cada tempo de sobrevivência de outro tratamento.

Por exemplo, o primeiro tempo de sobrevivência observado para o tratamento 1 é comparado com cada tempo de sobrevivência observado no tratamento 2 . Ou seja, $U_{16}$ representa o valor atribuído ao primeiro tempo de sobrevivência observado do tratamento 1 comparado ao sexto tempo de sobrevivência observado do tratamento 2. Cada comparação feita pode receber os valores $-1,0$ ou 1 , conforme indicado no Teste de Gehan.

No caso, $U_{16}$ recebe o valor -1 , pois o tempo de sobrevivência observado no tratamento 1 é menor que o tempo de sobrevivência observado no tratamento 2 $\left(x_{1}<y_{6}\right)$ e o tempo de sobrevivência observado no tratamento 1 é tempo de censura $\left(\delta_{1}=1\right)$.

Procedendo-se dessa maneira encontra-se os valores de $U_{i j}, i=$ $1, \ldots, 15 ; j=1, \ldots, 14$ (Quadro 3 ) e o valor da estatística

$$
W=\sum_{j=1}^{n_{2}} \sum_{i=1}^{n_{1}} U_{i j}=-21 .
$$




\begin{tabular}{|c|c|c|c|c|c|c|c|c|c|c|c|c|c|c|}
\hline $\mathrm{i} \quad \mathrm{j} \rightarrow$ & 1 & 2 & 3 & 4 & 5 & 6 & 7 & 8 & 9 & 10 & 11 & 12 & 13 & 14 \\
\hline 1 & -1 & -1 & -1 & 0 & -1 & -1 & -1 & -1 & -1 & -1 & -1 & -1 & -1 & -1 \\
\hline 2 & 0 & 0 & 0 & 1 & -1 & -1 & -1 & -1 & -1 & -1 & -1 & -1 & -1 & -1 \\
\hline 3 & 0 & 0 & 1 & 0 & 0 & 0 & 0 & 0 & 0 & 0 & 0 & 0 & 0 & 0 \\
\hline 4 & 0 & 0 & 0 & 1 & -1 & -1 & -1 & -1 & -1 & -1 & -1 & -1 & -1 & -1 \\
\hline 5 & 0 & 0 & 0 & 1 & -1 & -1 & -1 & -1 & -1 & -1 & -1 & -1 & -1 & -1 \\
\hline 6 & 0 & 0 & 0 & 1 & 1 & -1 & -1 & -1 & -1 & -1 & -1 & -1 & -1 & -1 \\
\hline 7 & 0 & 0 & 0 & 1 & 1 & -1 & -1 & -1 & -1 & -1 & -1 & -1 & -1 & -1 \\
\hline 8 & 0 & 0 & 0 & 1 & 1 & 0 & 0 & 0 & 0 & 1 & 1 & 0 & 0 & 0 \\
\hline 9 & 0 & 0 & 0 & 1 & 1 & 0 & 0 & 0 & 0 & 1 & 1 & 0 & 0 & 0 \\
\hline 10 & 0 & 0 & 0 & 1 & 1 & 0 & 0 & 0 & 0 & 1 & 1 & 0 & 0 & 0 \\
\hline 11 & 0 & 0 & 0 & 1 & 1 & 0 & 0 & 0 & 0 & 1 & 1 & 0 & 0 & 0 \\
\hline 12 & 0 & 0 & 0 & 1 & 1 & 0 & 0 & 0 & 0 & 1 & 1 & 0 & 0 & 0 \\
\hline 13 & 0 & 0 & 0 & 1 & 1 & 0 & 0 & 0 & 0 & 1 & 1 & 0 & 0 & 0 \\
\hline 14 & 0 & 0 & 0 & 1 & 1 & 0 & 0 & 0 & 0 & 1 & 1 & 0 & 0 & 0 \\
\hline 15 & 0 & 0 & 0 & 1 & 1 & 0 & 0 & 0 & 0 & 1 & 1 & 0 & 0 & 0 \\
\hline & -1 & -1 & 0 & 13 & 6 & -6 & -6 & -6 & -6 & 2 & 2 & -6 & -6 & -6 \\
\hline
\end{tabular}

Quadro 3 - Valores de $U_{i j}$, para o Teste de Gehan. 
Exemplo Ilustrativo 2

O conjunto de dados apresentado no exemplo ilustrativo 1 será utilizado para a obtenção de valores necessários para calcular a variância do Teste de Gehan.

\begin{tabular}{|c|c|c|c|c|c|c|}
\hline Tempos & Censura & Tratamento & $m_{i}$ & $M_{j}$ & $l_{i}$ & $L_{j}$ \\
\hline 1 & 1 & 1 & 0 & 0 & 1 & 1 \\
1 & 0 & 2 & 3 & 3 & 0 & 1 \\
1 & 1 & 2 & 0 & 3 & 1 & 2 \\
2 & 1 & 1 & 0 & 3 & 1 & 3 \\
3 & 0 & 1 & 2 & 5 & 0 & 3 \\
3 & 1 & 1 & 0 & 5 & 1 & 4 \\
4 & 1 & 2 & 0 & 5 & 1 & 5 \\
5 & 1 & 1 & 0 & 5 & 2 & 7 \\
5 & 0 & 2 & 1 & 6 & 0 & 7 \\
7 & 0 & 2 & 1 & 7 & 0 & 7 \\
8 & 0 & 2 & 1 & 8 & 0 & 7 \\
10 & 0 & 2 & 1 & 9 & 0 & 7 \\
10 & 1 & 2 & 0 & 9 & 1 & 8 \\
12 & 1 & 2 & 0 & 9 & 1 & 9 \\
16 & 1 & 1 & 0 & 9 & 8 & 17 \\
16 & 1 & 2 & 0 & 9 & 3 & 20 \\
\hline
\end{tabular}

Quadro 4 - Valores auxiliares obtidos para os conjuntos de dados.

O Quadro 4 apresenta os tempos distintos de sobrevivência de acordo com o tratamento que o indivíduo foi submetido e se o tempo é até a censura ou tempo até a falha.

A partir desses dados, são então observados:

$\boldsymbol{m}_{i}$, o número de falhas ocorridas no tempo i, por exemplo, no tempo 3, do tratamento 1 , ocorreram 2 falhas, $\log 0 m_{i}=2$;

$\boldsymbol{M}_{j}$, o número de falhas ocorridas até tempo $\mathrm{j}$, por exemplo, até o tempo 3 , do tratamento 1 , ocorreram 5 falhas, $M_{j}=5$;

$l_{i}$, o número de censuras ocorridas no tempo $\mathrm{i}$, por exemplo, no tempo 3 , do tratamento 1 , ocorreu 1 censura, $\operatorname{logo} l_{i}=1$;

$\boldsymbol{L}_{i}$, que é o número de falhas ocorridas até o tempo i, por exemplo, até o tempo 3 , do tratamento 1 , ocorreram 4 falhas, $\log o L_{j}=4$. 
Apêndice 2

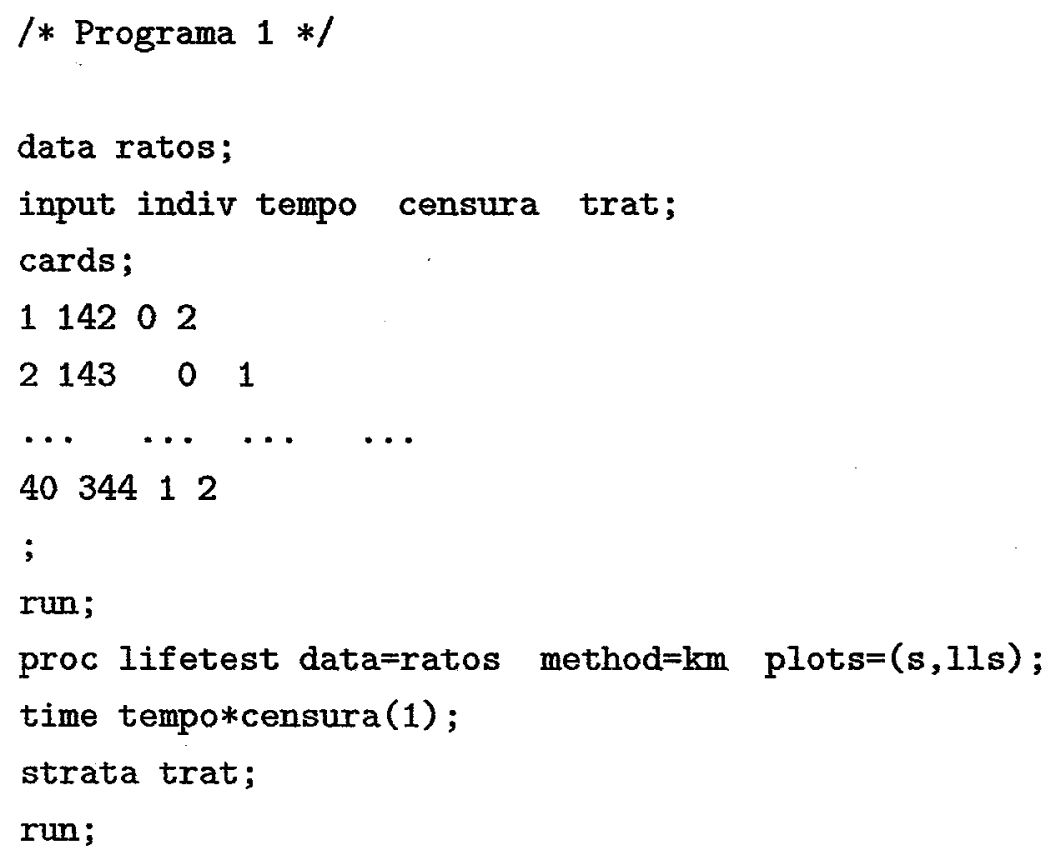




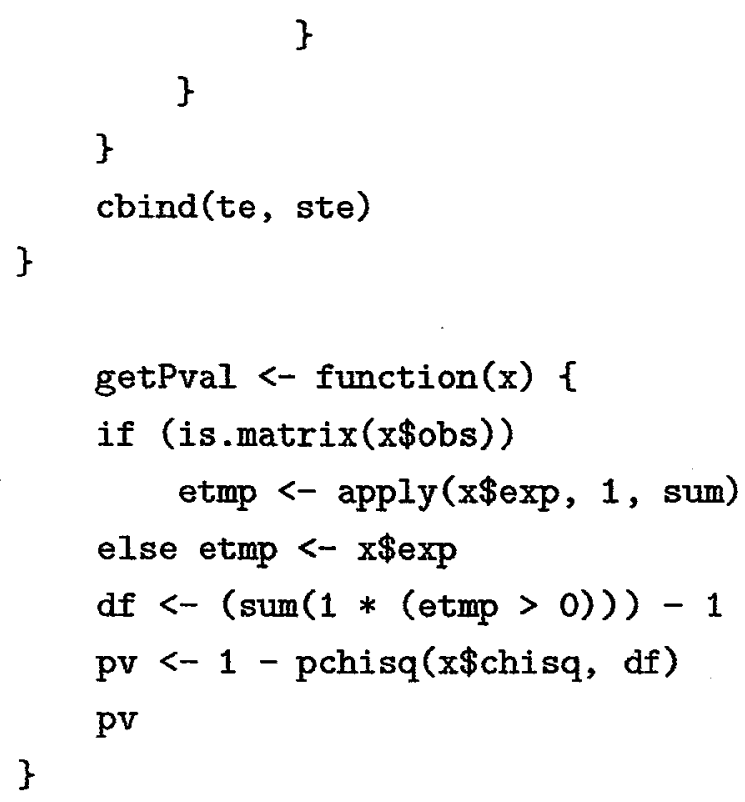




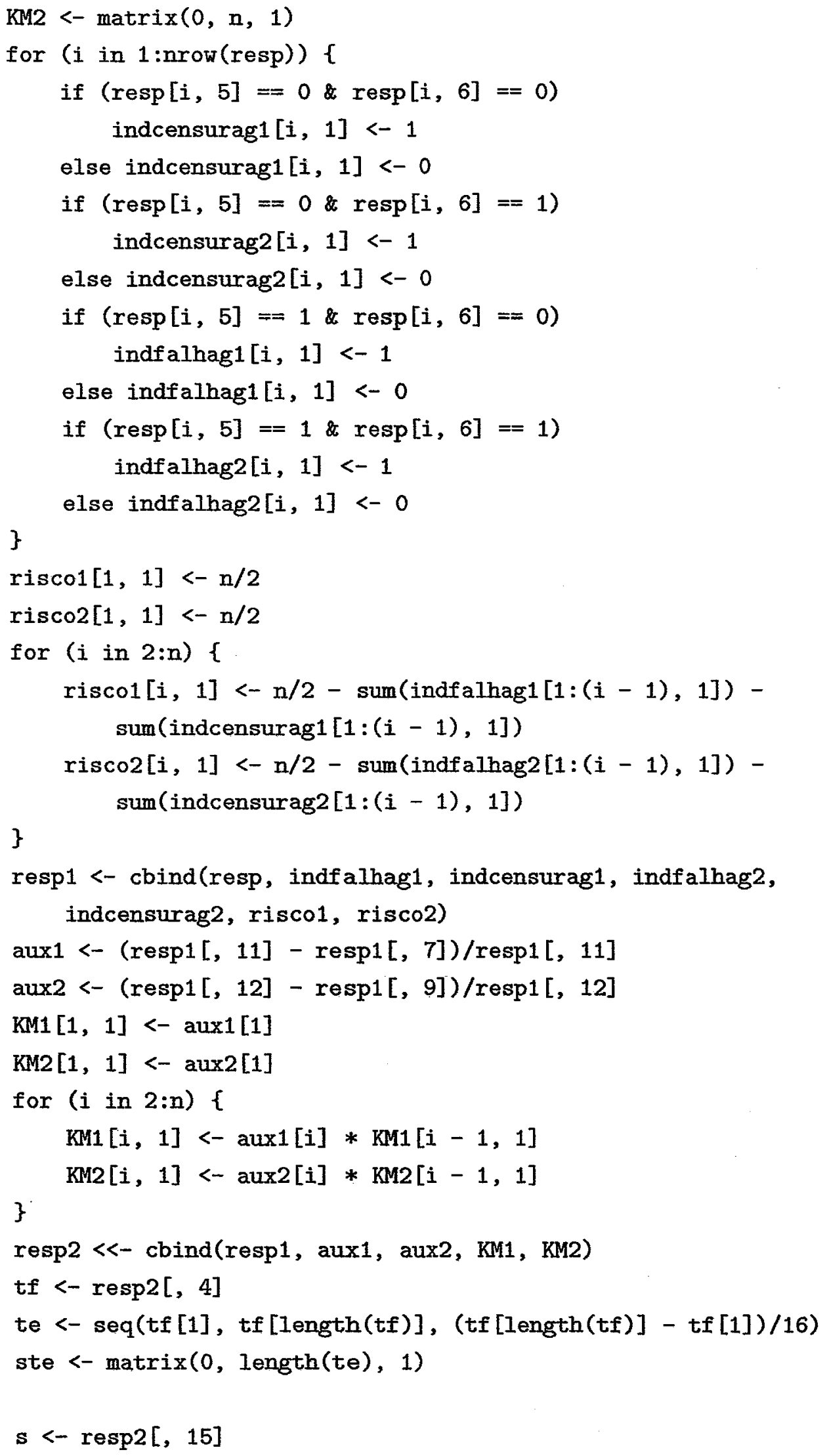




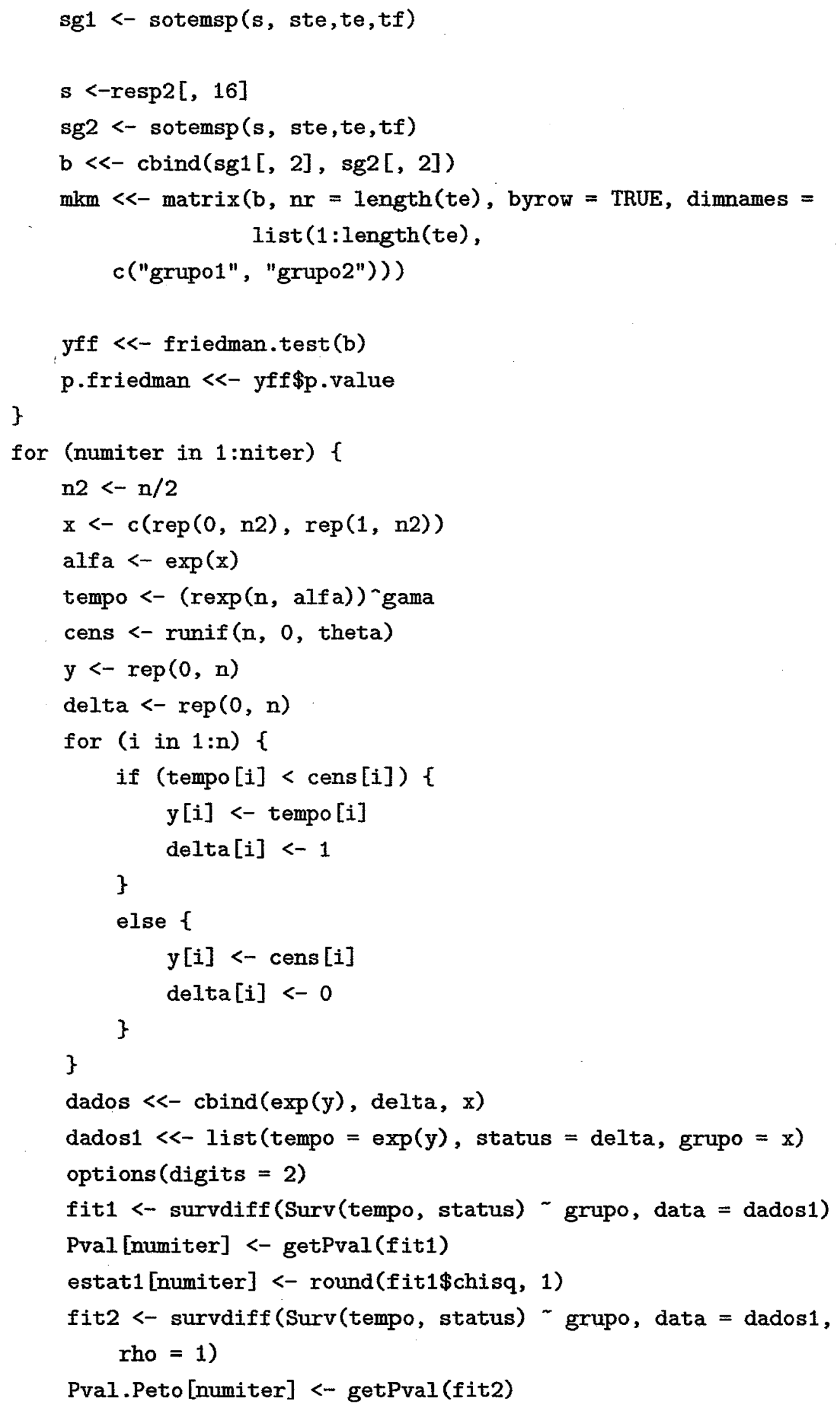




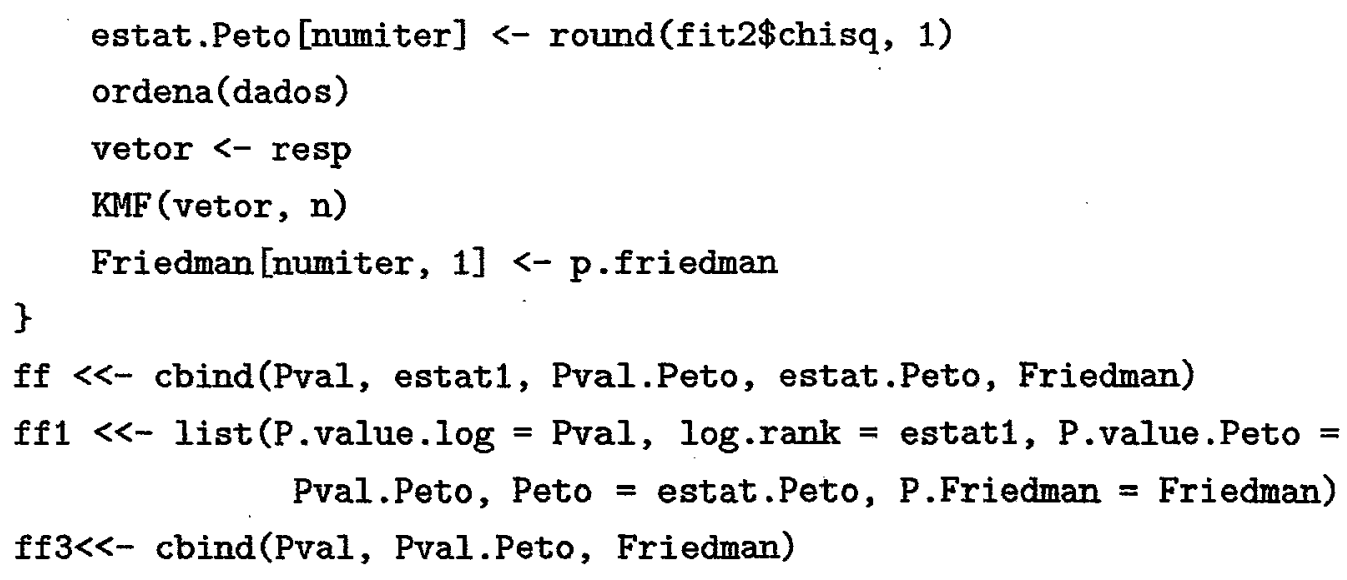


Apêndice 3

Conjuntos de Dados

Tabela 1: Tempos de vida de pacientes com Hepatite Viral Aguda, submetidos a dois tratamentos.

\begin{tabular}{|c|c|c|c|}
\hline Indivíduo & Tempo & Censura & Tratamento \\
\hline 1 & 1 & 1 & 1 \\
\hline 2 & 2 & 1 & 1 \\
\hline 3 & 3 & 0 & 1 \\
\hline 4 & 3 & 0 & 1 \\
\hline 5 & 3 & 1 & 1 \\
\hline 6 & 5 & 1 & 1 \\
\hline 7 & 5 & 1 & 1 \\
\hline 8 & 16 & 1 & 1 \\
\hline 9 & 16 & 1 & 1 \\
\hline 10 & 16 & 1 & 1 \\
\hline 11 & 16 & 1 & 1 \\
\hline 12 & 16 & 1 & 1 \\
\hline 13 & 16 & 1 & 1 \\
\hline 14 & 16 & 1 & 1 \\
\hline 15 & 16 & 1 & 1 \\
\hline 16 & 1 & 0 & 2 \\
\hline 17 & 1 & 0 & 2 \\
\hline 18 & 1 & 0 & 2 \\
\hline 19 & 1 & 1 & 2 \\
\hline 20 & 4 & 1 & 2 \\
\hline 21 & 5 & 0 & 2 \\
\hline 22 & 7 & 0 & 2 \\
\hline 23 & 8 & 0 & 2 \\
\hline 24 & 10 & 0 & 2 \\
\hline 25 & 10 & 1 & 2 \\
\hline 26 & 12 & 1 & 2 \\
\hline 27 & 16 & 1 & 2 \\
\hline 28 & 16 & 1 & 2 \\
\hline 29 & 16 & 1 & 2 \\
\hline
\end{tabular}

Fonte: Colosimo, 2001. p.3. 
Tabela 2: Tempos de sobrevivência de ratos, submetidos a dois pré-tratamentos.

\begin{tabular}{|c|c|c|c|}
\hline Indivíduo & Tempo & Censura & Tratamento \\
\hline 1 & 142 & 0 & 2 \\
\hline 2 & 143 & 0 & 1 \\
\hline 3 & 156 & 0 & 2 \\
\hline 4 & 163 & 0 & 2 \\
\hline 5 & 164 & 0 & 1 \\
\hline 6 & 188 & 0 & 1 \\
\hline 7 & 188 & 0 & 1 \\
\hline 8 & 190 & 0 & 1 \\
\hline 9 & 192 & 0 & 1 \\
\hline 10 & 198 & 0 & 2 \\
\hline 11 & 204 & 1 & 2 \\
\hline 12 & 205 & 0 & 2 \\
\hline 13 & 206 & 0 & 1 \\
\hline 14 & 209 & 0 & 1 \\
\hline 15 & 213 & 0 & 1 \\
\hline 16 & 216 & 0 & 1 \\
\hline 17 & 216 & 1 & 1 \\
\hline 18 & 220 & 0 & 1 \\
\hline 19 & 227 & 0 & 1 \\
\hline 20 & 230 & 0 & 1 \\
\hline 21 & 232 & 0 & 2 \\
\hline 22 & 232 & 0 & 2 \\
\hline 23 & 233 & 0 & 2 \\
\hline 24 & 233 & 0 & 2 \\
\hline 25 & 233 & 0 & 2 \\
\hline 26 & 233 & 0 & 2 \\
\hline 27 & 234 & 0 & 1 \\
\hline 28 & 239 & 0 & 2 \\
\hline 29 & 240 & 0 & 2 \\
\hline 30 & 244 & 1 & 1 \\
\hline 31 & 246 & 0 & 1 \\
\hline 32 & 261 & 0 & 2 \\
\hline 33 & 265 & 0 & 1 \\
\hline 34 & 280 & 0 & 2 \\
\hline 35 & 280 & 0 & 2 \\
\hline 36 & 296 & 0 & 2 \\
\hline 37 & 296 & 0 & 2 \\
\hline 38 & 304 & 0 & 1 \\
\hline 39 & 323 & 0 & 2 \\
\hline 40 & 344 & 0 & 2 \\
\hline
\end{tabular}

Fonte: Kalbfleisch \& Prentice, 1980. 
Tabela 3. Tempos de sobrevivência de 12 pacientes com tumor no cérebro.

\begin{tabular}{cccc} 
Indivíduo & Tempo & Censura & Tratamento \\
\hline 1 & 24 & 0 & 1 \\
2 & 30 & 0 & 1 \\
3 & 42 & 0 & 1 \\
4 & 15 & 1 & 1 \\
5 & 40 & 1 & 1 \\
6 & 42 & 1 & 1 \\
7 & 10 & 0 & 2 \\
8 & 26 & 0 & 2 \\
9 & 28 & 0 & 2 \\
10 & 30 & 0 & 2 \\
11 & 41 & 0 & 2 \\
12 & 12 & 1 & 2 \\
\hline
\end{tabular}

Fonte: Lee, 1980. p.127. 